\title{
EDITORIAL
}

\section{La endocrinología y los médicos generales}

$\mathrm{L}$ os programas de posgrado en endocrinología en Colombia son relativamente recientes. El primero que se creó fue en la Universidad Nacional de Colombia en el año de 1982, seguido de otros en Bogotá en las universidades Javeriana, Militar, Rosario, FUCS, y los establecidos en Medellin en la Universidad de Antioquia, siendo el último el de la Pontificia Universidad Bolivariana. Además, se creó el de endocrinología pediátrica de la Universidad de Antioquia. Estos posgrados forman en general dos endocrinólogos por año. Antes de esa época, los que ejercíamos como endocrinólogos nos habíamos formado en escuelas fuera del país.

El total de endocrinólogos que pertenecemos a nuestra asociación es de 146 miembros de número, que corresponden prácticamente al número total de endocrinólogos con formación académica en Colombia. Ejerciendo a lo largo del país, la mayoría estamos localizados en las grandes capitales como Bogotá, Medellín, Cali, Barranquilla, Cartagena, entre otras, con unos pocos en ciudades intermedias como Bucaramanga, Pereira, Ibagué, Pasto, Manizales, Cúcuta, Neiva y Villavicencio; pero existen poblaciones de cierta importancia en las cuales no hay endocrinólogos y los pacientes se ven obligados a ser tratados por otros especialistas o por médicos generales o a ser remitidos, con todo lo que eso implica, bajo el punto de vista médico, psicológico y económico.

La consulta del especialista en endocrinología está centrada en orden de frecuencia en diabetes, obesidad y trastornos tiroideos, siendo el resto de las patologías en ocasiones raras y muchas veces podríamos decir hasta "exóticas". Si consideramos que en Colombia el número de diabéticos puede llegar a más de cinco millones (no existen estudios epidemiológicos que abarquen todo el país, pero se considera por los que existen que el porcentaje podría llegar casi al $10 \%$ de nuestra población), pretender que con este número de especialistas se trate a esta población podría rayar en el delirio. La frecuencia de pacientes con diagnóstico de hipotiroidismo no la conocemos pero inferimos que podría ser muy similar o inclusive mayor.

La oportunidad para que un paciente "logre" poder "agendar" una cita con un endocrinólogo puede requerir en ocasiones hasta más de un mes, además de que hay colegas que ya no reciben pacientes de primera vez. Entonces, ¿qué se podría hacer?, ¿admitir más médicos para realizar la especialidad?, ¿crear más programas de especialidad en endocrinología? 0 ¿capacitar a los médicos generales y a los internistas para manejar este tipo de patología?

Esta última premisa a mi parecer podría ser la más lógica y realista. A la consulta del endocrinólogo llega un buen número de pacientes diabéticos o hipotiroideos que podrían ser manejados en forma racional y científica por el médico general (glucemias basales de no más de $150 \mathrm{mg}$ y TSH menores de 10, para poner un ejemplo), siempre y cuando en las diferentes facultades formen a sus estudiantes en estos temas y, sobre todo, les enseñen hasta dónde pueden actuar y cuándo deberán remitir. Además, los casos de cierta complejidad podrían ser manejados perfectamente por el médico internista que tiene una formación de tres años de posgrado y remitir al endocrinólogo casos más complejos, sea en diabetes, tiroides, suprarrenales, hipófisis, etc. Estamos copando nuestra consulta de endocrinología con casos que podrían ser manejados perfectamente por otros colegas y les estamos quitando a nuestros pacientes complicados y difíciles la oportunidad de ser vistos por el endocrinólogo.

El cambio deberá venir primero en mejorar la formación de pregrado en endocrinología. En algunas facultades se considera una rotación opcional y, por supuesto, hay muchos médicos que no han visto ni recibido formación en esta disciplina. El segundo punto importante es el de la atención, tenemos que hacer un llamado a las EPS para que racionalicen el envío de los pacientes al endocrinólogo, debería hacerse una especie de "triage" para determinar qué pacientes deberán visitar al endocrinólogo y, por último, educar a los pacientes para que aprendan cuándo deben pedir cita con el endocrinólogo.

La labor no es sencilla y, por supuesto, necesitaría un tiempo para poder concientizar tanto a las universidades como a los colegas y a los pacientes. Quiero, por intermedio de esta columna, abrir un debate y una reflexión sobre el tema, en unión con las diferentes facultades de medicina, las EPS, las sociedades científicas, bajo el liderazgo de nuestra Asociación Colombiana de Endocrinología, Diabetes y Metabolismo, pero a la larga serán ustedes, todos los médicos, los que tendrán la última palabra. Espero sus comentarios, aportes y críticas a esta propuesta.

\section{Enrique Ardila \\ Editor}

Revista Colombiana de Endocrinología, Diabetes y Metabolismo 